\title{
Online Retailing Paired with Kirana-A Formidable Combination for Emerging Markets
}

\author{
Piyush Kumar Sinha $^{1} \cdot$ Srikant Gokhale $^{2} \cdot$ Saurabh Rawal $^{3}$
}

Published online: 13 October 2015

(C) Springer Science+Business Media New York 2015

\begin{abstract}
In the light of the convenience provided by online and the omnipresent kirana (mom-and-pop equivalent) stores and low penetration of large format retailing, it is proposed that these two would be the dominant formats of retailing in the emerging economies. Four major factors have fuelled the growth of electronic commerce in emerging economies. First and foremost is the rapid penetration of technology, be it the broadband or the smart phones. Second is the fast adoption of the online medium by every major brand as a part of their sales as well as the marketing strategy. Large retailers have also opened stores in the virtual space. The third factor is the convenience and choices consumers derive through online shopping that adds value to time- and effort-strapped customers. This is further facilitated by services like cash-on-delivery, buy-back policies and many more. Finally, the increased real estate prices, higher operational costs and non-availability of good retail spaces have restricted the growth of larger physical stores.
\end{abstract}

Keywords E-commerce $\cdot$ Online retailing $\cdot$ Emerging markets · Omni channel $\cdot$ Kirana stores

\section{Introduction}

Even when online business represents less than $10 \%$ of retailing and about $1 \%$ of grocery retailing, it is disruptive and forces

Piyush Kumar Sinha

pksinha@iimahd.ernet.in

1 Indian Institute of Management Ahmedabad (IIMA), Vastrapur, Ahmedabad 380015, India

2 Al-Sorouh Holding, Kuwait City, Kuwait

3 Alberta University, Edmonton, AB, Canada every other format to rethink their strategies. Initial online retailing experiments in the grocery sector, such as Webvan and Peapod, were unsuccessful; however, some recent initiatives in India are expanding rapidly. Online grocery retailers such as bigbasket.com and grofers.com are expanding to multiple cities, and large online retailers like Amazon, Flipkart and Snapdeal have also announced their intention to sell groceries in India [18].

A time-starved younger population, along with increasing disposable income, provides substantial scope for growth in ecommerce. The format saves time and fuel for consumers, demands no expensive real estate investment for expansion, and is accessible even through a smartphone. In contrast, large-format physical retailing in India is facing many hurdles such as rising real estate prices, lack of viable store locations, high overheads, underdeveloped back-end infrastructure, pilferage and lack of trained manpower. The limitations of largeformat retailing in countries like India and China facilitate the explosion of online retailing.

With the entry of online retailers in the grocery sector, we may be witnessing another disruption which large-format retailing could not achieve - reduction of the market share of small retailers. This has already occurred in the case of music (almost totally), books (substantially), and mobility products (to a large extent). Large-format retailers such as supermarkets have not been able to take business away from kirana stores in India, even after offering discounted products.

As food and grocery retailing constitutes almost $60 \%$ of total retail sales in India and China, and small-format shops comprise more than $96 \%$ of retail stores [31], this category is expected to define the future growth of online retail formats in India. As online and kirana stores have very distinct business models, whereas the 'big box' retailers offer values similar to online stores (a wider assortment and lower prices), it is suggested that these formats can complement each other and together deliver very high value to consumers. 
The paper first outlines the factors affecting the growth of online retailing. In addition to the factors of technology, consumers and brands, the paper highlights the role of the physical retail landscape in the explosion of online retailing. It describes kirana stores, which have received littler research attention to date; it then uses a business model perspective to demonstrate that kirana stores deliver a unique set of values. The section on multi-channel outlines how consumers choose and shift between channels. It presents evidences of cannibalisation as well as complementarity and shows how consumers tend to favour a high-service channel, especially for a category like grocery. The paper then compares and contrasts online grocery and kirana stores and concludes that they would be better off complementing rather than competing with each other.

\subsection{Online Retailing}

Online retailing contributes about $6 \%$ of total retail sales in developed nations and about $4 \%$ in the BRICS countries (Brazil, Russia, India, China and South Africa) and other developing nations. In 2013, the total size of the retail industry in developing-country markets was estimated at $\$ 3.3$ trillion and $\$ 5.5$ trillion in the top five developed markets. Over 20082013, the retail industry in the top five developed markets grew at a compound annual growth rate (CAGR) of $0.81 \%$, whereas the equivalent growth rate in the developing markets was $9.86 \%$ [31]. This rapid growth of buying of goods and services online could be attributed to four major factors.

First is the rapid adoption of digital technology, especially with smartphones increasingly being used to access the internet. This happens due to hedonic motivation, price value and habit, in addition to other factors of technology adoption [37]. The increase in perceived security and reduction in perceived risk has also contributed to its faster adoption [29].

The second enabler of the penetration of online retailing has been the convenience of shopping, the choices available and the ease of access. For example, Indian men (32\%) are far more likely than Indian women (12\%) to have internet access, and men are more than three times as likely to be digitally influenced (14 vs $4 \%$ ); they value the convenience of shopping from home $(37 \%)$, discounts $(30 \%)$ and wider product assortments (29\%) when buying online [20]. While these factors attract customers to visit a website, factors influencing patronage change with categories [19]. Ease and security of payment has contributed significantly to growth; almost all online retailers in India offer cash on delivery (COD) to mitigate the problem of low penetration of credit cards and online payments. It has also reduced the perceived risk of getting the right product. Although it costs the companies more to manage and there are risks of pilferage [17], the reputations of online stores that support COD are much better than those of stores that do not [6]. Online retailers offer a $100 \%$ cash-back policy, a facility that most brick-and-mortar players do not provide, and telephone and chat services have helped customers become comfortable with the format. Most sites offer heavy discounts and attractive offers year-round. Promotional offers have always attracted customers [11], and these motivate the customers to try out buying on the internet and in many cases switch from the physical stores to virtual stores.

The third factor contributing to the explosion of online commerce is its adoption by brick-and-mortar retailers, who once used the internet solely as a communication tool. One study found that $61 \%$ of Singaporean companies were using the internet for electronic commerce [33]. In China and Mexico, more than 70 and $50 \%$ of companies, respectively, are e-commerce enabled. In Brazil, more than $95 \%$ of businesses are expected to use the internet for business purposes by 2020 [31]. An integrated omni-channel strategy is expected to enhance offline experiences [16]. This trend of going online is not restricted to large businesses; many initiatives like Shopify, Alibaba and Infibeam have helped small businesses, self-employed people and even housewives to start businesses online. Several online retailers, including Amazon and Flipkart, are becoming marketplaces and host many physical retailers. Social media has also facilitated this transition; of the 150 million Indians using the internet today, more than a third are on Facebook [38].

The physical retail landscape (the fourth factor) in India and China is very different to that in more developed countries. While in many countries, online retailing arrived long after large-format retailing was well entrenched, it came much sooner in India and China. With access not being limited by geography and online retailers providing a wide range of products at very attractive prices, the online format has found acceptance in smaller towns and rural areas where large-format retailing is yet to enter. In India, almost $40 \%$ of the sales of many large online stores come from small- and medium-sized towns and rural areas which are not being serviced by largeformat retailers.

There are more than 14 million physical stores in India, constituting more than $99 \%$ of small retailers. About six million of these are small kirana stores. Leading national and regional brands reach more than $75 \%$ of these stores through direct and indirect channels. In the period 2008-2013, storebased retailing in India generated about $\$ 435$ billion in revenue and non-store retailers about $\$ 5$ billion; store-based retailing grew at a CAGR of $6 \%$, whereas the rate for non-storebased retailing was $15 \%$ [18]. Large-format chain retailers have found it challenging to grow and become profitable; one of the primary factors has been the steep rise in real estate prices, which comprise up to $10 \%$ of sales in India as compared to 3-4\% in developed economies [35]. The availability of good retail spaces is low, despite more properties being developed. Wherever hypermarkets have low penetration, online stores have found wider acceptance [18]. 


\subsection{Kirana Stores}

Kirana stores are the typical Indian grocery stores. A kirana store has an over-the-counter format ranging from 100 to $1000 \mathrm{ft}^{2}\left(9.3-93 \mathrm{~m}^{2}\right)$ in floor area; more than $75 \%$ of them are smaller than $500 \mathrm{ft}^{2}\left(46.5 \mathrm{~m}^{2}\right)$. Kirana stores compete by providing a mix of merchandise, credit, home delivery and personalised services.

A kirana store looks like a mom-and-pop store but behaves like a supermarket. Mom-and-pop stores mainly exist to meet emergency and fill-in requirements, whereas kirana stores meet the stock-up requirements too. Many of them have upgraded their stores with better lighting, displays, product offerings and air-conditioning. They stock 1000-8000 SKUs, with established national and regional brands comprising more than $50 \%$ of their offerings. They get a margin of $7-$ $20 \%$ on these products, averaging about $14 \%$ as compared to about $20 \%$ for large-format stores. Many brands follow a credit system for incentivising the selling of their full product range. Incentives to kirana stores are paid quarterly based on the accumulated credits linked to the sales target of each of the brands in the range.

The other $50 \%$ of kirana store offerings includes local and unbranded products that give them better margins (20-60\%), similar to those of private labels at large-format stores. They seldom run any promotions or give discounts unless offered by the manufacturers. Consumers do not find the prices very high, even when the stores sell at the prices printed on the packaging. Kirana stores localise their merchandise based on the ethnicity of the trading area, especially with regard to food and other edible products. Often several stores are clustered in a given locality. There is also a sense of cooperation among these stores; if a store does not have the products that the consumers want, it will procure them from a neighbouring store immediately while the customer is still in the store or deliver them to the customers' homes.

In order to reach India's six million kirana stores, companies follow a multi-channel strategy. These stores are serviced by distributors (direct channels) and wholesalers (indirect channels). The direct channels reach about $20-30 \%$ of the stores and are managed by the distributors. Kirana stores in this group usually do not order, except in case of emergency; they are visited by the distributors' salespersons, who take orders and send the required goods. Some of the leading brands service these outlets every 3 days, reducing stocking requirements and improving the ROI for the stores. Wholesalers supply smaller stores in larger towns and most retailers in smaller towns and rural areas. Stores from small towns and rural areas visit wholesale markets in nearby towns to buy their merchandise; the rest are serviced through wholesalers located in the marketplaces where retailers come and buy. Some wholesalers deliver direct to retailers. Many kirana stores also buy from hypermarkets, especially during deep discount offers.
Most established brands, contributing to about $30 \%$ of purchases by the stores, sell on advance payment or cash; the rest are bought on a credit or consignment basis. Credit periods vary from 1 week to 2 months. In all cases, kirana stores are provided with return as well as replacement facilities. This reduces their cash requirement and the risk of unsold inventory and means they are ready to stock newer brands and variants. In most cases, the arrangement between the distributor/wholesaler and the kirana stores is informal, with payment in cash. Banking transactions are common only among larger kiranas and with major brands.

A large proportion of kirana operators own their stores. This is considered an investment, and they avoid rental expenses. In fact, due to the Indian real estate boom, the value of their stores has multiplied. Staff employment is informal. Most kirana stores employ fewer than 10 people and are not obliged to provide welfare; salaries are low. Many kirana employees come from the extended families or the villages of the owners. Bicycles are used for home deliveries.

\subsection{Business Models in Retailing}

Consumers shop using different formats based on the values that they derive [35]. Store formats are chosen based on availability, accessibility, ambience and affordability, as well as the cost of shopping tasks [3]. It is found that consumers tend to choose new formats like online based on cognitive factors, whereas established formats like kirana are chosen based on affect [1]. Studies indicate that the extent of adoption of formats also depends on chronological order of first use [30].

A format represents a combination of particular levels of each element of the retailing mix, such as product assortment, pricing, location, service, ambience, customer interface and the level and type of services offered [26]. Each format tends to maximise on one value dimension supported by other dimensions. While a retailer would use one or two of these as primary variables, the interaction among them makes each format a unique business to manage. In any product category, customers choose the format that fits their needs most; they choose different formats from the same product categories based on their requirements [1, 5]. For instance, food can be purchased from convenience stores, grocery stores, warehouse stores, cash and carry stores, online grocers, kirana stores and mass merchandisers.

The format chosen by the retailers determines the system required to deliver the values promised to their target segments. This system is designed by identifying and managing the selected retailing activities that fulfil the desired customer experiences. While the elements of retailing mix remain the same, each format mixes them up differently to create a customised business model. Hence, retailers using the same format can follow different business models based on the 
segments they serve, context in which they operate and their value appropriation objectives.

A business model is defined as a system of interdependent activities that transcends the focal firm and spans its boundaries [40]. Through this activity system, the firm creates value and appropriates a share of that value. It is anchored on two sets of parameters: design elements (content, structure and governance) and design themes (novelty, lock-in, complementarities and efficiency). These parameters interlock to create and deliver value to all stakeholders. The concept of business model becomes far more pertinent when firms unbundle themselves to derive more value for each of the stakeholders [13]. Success depends on the bundling and re-bundling by focusing on the core sliver of the value chain that the corporation chooses since the business economics of each sliver are different. Also, each of the slivers may be managed by a different business and legal entity. Retailers are a good example of such debundled organisations, which focus on providing choices to customers by controlling only one end of the value chain. Online retailers, for example, do not stock all merchandise, depend on courier companies for delivery, set up outsourced call centres for customer service and manage optimization in search and personalised promotional programmes. Many of them also create marketplaces in which different brands and suppliers 'showcase' their merchandise and are responsible for the delivery and quality of their products and services.

Five circumstances seem to necessitate a new business model. These are disruptive solutions, new technology, markets that require continuous refinement or customization, fending off disruptors and responding to a shifting basis of competition [21]. Online retailing is one such disruption, which has forced all formats of retailing and multiple categories of product sellers to rethink their business models. Retailers have innovated with their business models to enhance value creation and appropriation beyond the levels afforded by traditional approaches to retailing [34]. They tend to operate around customer value proposition, profit formula, key resources and key processes to differentiate themselves (Table 1).

Proposition-1 Kirana stores survived the emergence of new channels as they follow a business model that helps them deliver high value while maintaining profitability.

Table 1 Business model design for large format, online and kirana stores

Business model design for different formats

\begin{tabular}{|c|c|c|c|c|}
\hline \multirow[t]{2}{*}{ Elements } & \multirow[t]{2}{*}{ Design theme } & \multicolumn{3}{|l|}{ Key processes } \\
\hline & & Large format & Online & Kirana \\
\hline \multirow[t]{8}{*}{ Value appropriation } & \multirow[t]{4}{*}{ Operational efficiency } & Reduce assortment & $\begin{array}{l}\text { Enlarge assortment-multi-category } \\
\text { catalogue providing high width } \\
\text { and high depth }\end{array}$ & $\begin{array}{l}\text { Focused assortment- single category } \\
\text { and high width and medium depth }\end{array}$ \\
\hline & & Implement a fast inventory turnaround & $\begin{array}{l}\text { Warehouse fast moving categories } \\
\text { and SKUs }\end{array}$ & Supplier-based merchandising \\
\hline & & Self-service model & Self-service shopping & Prefer brands with established demand \\
\hline & & "Name your own price" model & Delivery at home & $\begin{array}{l}\text { Over the counter, order on phone; } \\
\text { pick up from store as well as } \\
\text { home delivery; order taking by } \\
\text { personal visit at home }\end{array}$ \\
\hline & \multirow[t]{2}{*}{ Operational effectiveness } & Leverage complementarities & Personalisation & Convenience - time and location \\
\hline & & Adjacency model & Inventory and logistics & Personal touch \\
\hline & \multirow[t]{2}{*}{ Customer lock-in } & \multirow[t]{2}{*}{$\begin{array}{l}\text { Enduring consumer relationships } \\
\text { via multichannel processes }\end{array}$} & Customer service & Replacement policies \\
\hline & & & Promotions & Home delivery of single items too \\
\hline \multirow[t]{9}{*}{ Value creation } & Customer efficiency & $\begin{array}{l}\text { Innovative format which facilitates } \\
\text { the shopping experience }\end{array}$ & $\begin{array}{l}\text { Search algorithms } \\
\text { Data analytics - personalised } \\
\text { catalogues }\end{array}$ & Low search and least effort \\
\hline & \multirow[t]{2}{*}{ Customer effectiveness } & \multirow{2}{*}{$\begin{array}{l}\text { Rely on stakeholders to determine } \\
\text { the optimal depth of assortment } \\
\text { and supporting services }\end{array}$} & Suggestive selling & Suggestive selling \\
\hline & & & Cross-selling & Cross-selling \\
\hline & \multirow[t]{3}{*}{ Customer engagement } & \multirow[t]{3}{*}{ Rely on added value tie-ins } & Availability & Personal relation \\
\hline & & & Product delivery & Community-based equity \\
\hline & & & Customer service & \\
\hline & \multirow[t]{3}{*}{ Profit formula } & Surplus from operations & Market valuation & Surplus from operations \\
\hline & & \multirow[t]{2}{*}{ Large customer base } & Consumers as assets & \multirow[t]{2}{*}{ Small and designated customer base } \\
\hline & & & $\begin{array}{l}\text { Profit from customer data-based } \\
\text { other business }\end{array}$ & \\
\hline
\end{tabular}




\subsection{Multi-channel Retailing}

Multi-channel retailers have attempted to leverage store assets for online fulfilment purposes but with mixed results with regard to serving consumers or increasing profitability $[15$, 24]. This allows consumers to purchase products online and pick up or return those products at a nearby store. These pickup and return options provide synergies between "bricks" and "clicks" locations that cannot be replicated by pure online competitors. Compared with traditional retailers, online counterparts are at a disadvantage in that consumers of the former are able to take possession of and use products immediately or take them home [8]. Pickup and return options provide similar benefits for online shoppers, letting consumers receive products more quickly and (potentially) more conveniently, avoid additional shipping costs, and immediately obtain credit for returned products. Retailers also benefit from opportunities to reduce shipping costs and pool channel demands at their stores [10].

Studies on cannibalisation across channels also indicate mixed results. Some scholars indicate that online retailers may lead to negative spillover effects from one channel to another or be a zero-sum game without benefits [36]. Some studies have found only weak and insignificant cannibalisation of physical stores resulting from online stores [14]. Some studies suggest that online channels complement rather than replace physical channels [2]. Others found that online channels provide significant improvements in sales, cost, inventory, and returns on investment. The timing of online channel adoption may not be significant, but having a local store presence does improve performance [39]. There is evidence of the moderating role of channel integration in non-availability and switching behaviour [4]. In addition, due to the disutility costs of purchasing online and substantial offline transportation costs, when a store opens locally, people tend to move away from online stores. Offline entry also decreases consumers' sensitivity to online price discounts and the breadth of the product line at a local retail store does not affect purchases [9].

Adding an online sales channel helps lower a retailer's average inventory costs. At early stages of multi-channel retailing, this outweighs the decline in sales due to cannibalisation. It should be noted that retailer-specific resources mitigate this negative effect: large retail companies attain higher long-term market share and net income as they embrace multi-channel retailing, and companies with longer catalogue experience achieve higher gross margin [30]. It has also been found that offline perceived service value increases online perceived value; offline value has a stronger effect on overall loyalty than online value; and online service complexity and internet adoption moderate the influence of service value on overall loyalty. A higher degree of customer convenience orientation as against risk aversion and service orientation may create a shift to online from physical stores. However, the desire for service, rather than risk aversion, could move customers away from online to physical stores [22].

Proposition-2 Online retailers do not cannibalise the sales from kirana stores due to kiranas' high-service levels and the high convenience orientation of customers.

\subsection{Kirana and Online Retailers}

A comparison between online and kirana stores indicates that each category has its own strengths and provides some similar and some different services (Table 2). Kiranas compensate for their limitations of size and merchandise with a very high level of service, including home deliveries even for a single item without any extra charge. They serve all types of shopping tasks (fill-in, emergency and stock-up). Most customers would collect from the store. Kiranas sell bread and delicatessen items as well as fresh vegetables, fruit and meat, but few offer alcoholic drinks and only a few in a given cluster would sell eggs. Prices of branded and packaged products do not vary among stores. Products which are sold loose - cereals, pulses, oil, savouries - do not carry any price indicators and kirana stores charge different prices. They sell local brands or unbranded items at less than advertised prices.

Online grocery stores, on the other hand, provide access, variety, price and convenience. They enable consumers to spend more time on other activities and offer them more convenient shopping. Online stores have low set-up costs due to a low requirement for real estate. They stock only fast-moving goods, reducing their inventory costs. However, their operating costs are higher than those of other formats. Their customer acquisition costs are higher. Compared to physical stores, they need to spend on fulfilment. By some estimates, they would not deal with any merchandise for which the fulfilment cost exceeds $10 \%$ of sales price. Online stores operate at a gross margin of about $9 \%$, as they sell at lower prices through deep discounts. Consequently, except for those dealing in services, or products with higher ASPs or those selling to focused customer segments, most online retailers are yet to become profitable.

So far, most online retailers operating in India are selling non-grocery products. Numerous reasons for this exist. Food shopping involves purchasing a basket of goods [12] that may be both perishable and heterogeneous [7]; it is also subject to habits, everyday routines and a host of related activities like meal planning, preparation and cooking [27]. Food purchases are necessary, repetitive and seasonal, and many customers like to physically touch goods before buying. Although most kirana stores sell dry groceries and packaged goods, touch becomes important when customers buy grains, cereals and pulses and especially vegetables and fruit. Finally, grocery 
Table 2 Operation of online and kirana

\begin{tabular}{lll}
\hline Dimensions & Online & Kirana \\
\hline Choice to consumer & Very high & Sufficient \\
Assortment & Multi-category and very wide & $\begin{array}{l}\text { Multi-category and sufficiently wide } \\
\text { Merchandise mix }\end{array}$ \\
& Mostly known brands & $\begin{array}{l}\text { National, regional and local brands and unbranded; } \\
\text { imported brands }\end{array}$ \\
Access & Easy & Easy \\
Timings & $24 \times 7 ; 365$ days & Early morning to late night; opens the shop even \\
& & late night or on holidays on special request \\
Home delivery & Yes & Yes \\
Touch and feel & Low & Low \\
Credit & No & Yes \\
Supplies & Wholesalers/distributors & Wholesalers/distributors \\
Platform & Single store or marketplace & Single store but clustered (several of them near each other) \\
Buying & Bulk & As per order \\
Discounts & Yes & No \\
Replacement & Yes & Yes \\
Cash back & No & Yes \\
Credit/debit card & Yes & Many of them \\
Personalised service & No & High \\
Order on telephone & No & Yes \\
Order on SMS & No & Many of them \\
\hline & &
\end{tabular}

products tend to have a low value-to-weight ratio [32], leading to higher cost of fulfilment and warehousing.

Proposition-3 Kirana stores and online stores complement each other as they offer many similar values, with kirana stores providing localisation and online providing personalisation and choice.

Kirana stores remain profitable due to lower operating costs and higher margins. They do not give discounts or markdowns on merchandise with higher sales, especially leading brands (Table 3 ). The cost of home delivery is close to zero since the shop assistant also delivers. They use bicycles or walk to the customers' premises. The customers' acquisition

Table 3 Complementarities between kirana stores and online retailers

\begin{tabular}{lll}
\hline Dimensions & Kirana & Online \\
\hline Merchandise & Mainly food & Mainly non-food \\
Assortment & Focused and localised & $\begin{array}{l}\text { Multi-category and } \\
\text { very wide }\end{array}$ \\
Cost of operations & Low & High \\
Loyalty & Very high & Low to medium \\
Switching cost & High and psychological & Low and economic \\
Fulfilment cost & Low & High \\
Acquisition cost & Low & High \\
Choice & Affective & Cognitive \\
Localisation & High & Low \\
Conversions & High & Low \\
\hline
\end{tabular}

costs are minimal as they live near the store. Sales assistants visit homes to take orders. Advertising costs are minimal; at most, they would use inserts in the local newspaper to announce the opening of the store, and a large signboard, usually sponsored by one or more brands. Sometimes, they carry a banner outside their store to announce initial offers; in most cases, these are also supported by the brands. Consumers choose the store based on word of mouth references and most remain loyal, as the overall value delivered is much higher that just price and merchandise mix.

Kirana stores continue to flourish in India despite several inefficiencies. They do not derive much value from buying or maintaining efficient inventory control. In some cases, it was found that almost $30 \%$ of inventory had remained unsold for more than 6 months (local suppliers had placed these goods on consignment). They also stock infrequently bought merchandise, sometimes due to shopkeepers buying it after inquiries from just a few customers.

A kirana store is an established format and follows a demand fulfilment model, whereas online stores face a demand creation challenge; the format is yet to be accepted as a primary shopping channel for many product categories, in particular, groceries. Consumers have started buying groceries online, but they are still experimenting and tend to exhibit significantly more exploratory behaviour than those in taskoriented situations [28]. Consumers are still evaluating the format and tend to behave more cognitively. It is expected that until consumers have become familiar with online retailing, the format will still be chosen cognitively, as against a kirana store, where the format choice is more affective [1]. 
Consequently, in most cases, the basket size of an online grocery customer is not very large. High proportions of them live in areas which are developing or remote and do not have good penetration of kirana stores; some are using this channel for emergency or fill-in purposes. Low per capita purchase affects customer profitability, so while each customer buying from a kirana is profitable, online grocery retailers must struggle to cross-subsidise their customers. Conversion in online retail is less than $5 \%$, whereas it is close to $100 \%$ in the case of kiranas.

Proposition -4 Online stores will work in areas where there is less kirana penetration. In all other places, they will need the support of kirana stores for fulfilment and basket composition until online grocery purchasing reaches a sizable proportion.

\section{Conclusion}

As the retail industry has become more organised, it has been expected that kirana stores would be among the losers [23]. The Indian government and stores have taken action to mitigate the negative effects; however, since the impact of largeformat physical stores has been limited, small stores have not taken industry-wide action, though this has been the main reason for the FDI being restricted to a minority stake. With online retail not restricted by physical trading area, the impact may be different. Consumers have shown preferences towards buying brands and products with lesser perceived risk. In addition, a younger population becoming digital natives, buying online and through smartphones, may take higher-spending customers away from kirana stores.

However, given high operating costs and initial experimentation by customers, it is suggested that to succeed in selling groceries in India, online retailers will have to work in cooperation with kirana stores. Such a synergistic model will not only complement their efforts but compensate for their weaknesses. For instance, kirana stores provide convenience but not a large and mixed assortment. Online retailers can support them by providing a larger product range. They can partner with brands and use their systems of distributors and wholesalers for serving their customers. This way, they can also offer merchandises to kirana stores at better prices. They can work as a demand-agglomerating platform for small retailers who have to depend on their wholesalers/distributors for their assortment. Their offer may also include online stores' private labels. In fact, they can work as buying centres or membership clubs.

The heterogeneity of the consumer basket can be managed by partnering with multiple kiranas; this would also build a larger basket size. Some online retailers have started supplying fruit, vegetables, eggs, milk, dry groceries, and ice cream from different stores to the same customers. Online retailers can add value by bringing the benefits of being a marketplace. Besides getting a larger assortment to choose from, consumers can still buy from their primary kirana store. In addition, they can choose from any other store nearby in case of nonavailability at their regular store. Each kirana can benefit from an e-store, for which they have neither the resources nor the capability to create for themselves. The challenge that online stores face is delivery, as these orders will be serviced by different stores and the deliverers from these stores may arrive at the customers' premises at different times. How long and what kinds of customers would patronise these online stores is yet to be established.

Kirana stores could become pick-up points for customers ordering online. However, due to the small size of most stores, they will not be able handle large numbers of orders. Nevertheless, kirana stores can equip themselves with the technology to receive orders from internet-enabled devices such as tablets and mobile phones. The ubiquitous kirana can enhance its accessibility to consumers through the medium of the internet, resulting in a larger catchment area for each store. The online retailer will be able to reduce its inventory, delivery and other overhead costs.

Online grocery stores selling to a targeted and more geographically concentrated customer segment through kiranas may reach profitability faster than larger ones due to their smaller catchment/fulfilment area. However, retailers will need to address the challenges of resource constraints, channel integration issues, staff support difficulties and cultural issues in integrating the two formats [25]. As the scale of business through online stores is not very large, they are being tested even by the kirana stores. Currently, the expectation from kirana stores is not high since the responsibility of customer acquisition as well as delivery is with the online retailers. Channel integration and conflict issues will emerge when online retailers gain scale; companies that develop plans to manage these situations will benefit in future. Another point on which online retailers need to focus is servicing a large number of scattered customers, which will require strict checks on customer acquisition and fufillment costs. In other products, these become tenable with scale; in the case of groceries, a new business model will have to be developed which is modular, profitable at smaller scale and easily replicable.

Developing nations that have had low internet penetration along with low penetration of large-format stores are poised to become attractive markets for electronic commerce in the coming years. The inability of organised retail to create a strong presence in these countries will be further dampened by the growing number of internet users who will largely prefer to shop through the internet and or shop from nearby traditional stores. Rural retailing is likely to continue to be dominated by small retailers, and therefore, they would be expected to derive a larger benefit by associating with online retailers. Internet penetration in rural areas will increase 
substantially due to smartphones. The reach of a combined traditional-online model could easily be extended to rural geographies to serve the enormous base of the Indian retail pyramid. Challenges exist, but a firm with an omni-retail strategy that merges the two formats - online and kirana - may prove to be a formidable force to service the large and diverse Indian population. The strategy is likely to be similarly effective in the BRICS and other large developing countries.

\section{References}

1. Anand KS, Sinha PK (2009) "Store format choice in an evolving market: role of affect, cognition and involvement". Int Rev Retail Distrib Consum Res 19(5):505-534

2. Avery J, Steenburgh TJ, Deighton J, Caravella M (2012) Adding bricks to clicks: predicting the patterns of cross-channel elasticities over time. J Mark 76:96-111

3. Bell DR, Ho TH, Tang CS (1998) Determining where to shop: fixed and variable costs of shopping. J Mark Res 35(3):352-369

4. Bendoly E, Blocher JD, Bretthauer KM, Krishnan S, Vankataramanan MA (2005) Online/in-store integration and customer retention. J Serv Res 7(4):313-327

5. Bhatnagar A, Ratchford B (2004) A model of retail format competition for non-durable goods. Int J Res Mark 21:39-5

6. Chiejina C, Olamide SE (2014) Investigating the significance of the 'pay on delivery' option in the emerging prosperity of the Nigerian e-commerce sector. J Mark Manag 5(1):120-135

7. De Kervenoael R, Soopramanien D, Elms J, Hallsworth A (2006) Exploring value through integrated services solutions: the case of egrocery shopping. Manag Serv Qual 16(2):348-445

8. De Koster R (2003) Distribution strategies for online retailers. IEEE Trans Eng Manag 50(4):448-457

9. Fernández-Sabiote E, Román S (2012) Adding clicks to bricks: a study of the consequences on customer loyalty in a service context. Electron Commer Res Appl 11(2012):36-48

10. Forman C, Ghosh A, Goldfarb A (2009) Competition between local and electronic markets: how the benefit of buying online depends on where you live. Manag Sci 55(1):47-57

11. Grewal D, Krishnan R, Baker J, Borin N (1998) The effect of store name, brand name and price discounts on consumers' evaluations and purchase intentions. J Retail 74:331-352

12. Gronow J, Warde A (2001) Introduction. In: Gronow J, Warde A (eds) Ordinary consumption. Routledge, London, pp 1-8

13. Hagle III J. and Singer M. (1999), "Unbundling the corporation", Harvard Business Review, March-April, 133-141

14. Herhausen D, Binder J, Schoegel M, Herrmann A (2015) Integrating bricks with clicks: retailer-level and channel-level outcomes of online-offline channel integration. J Retail 91(2):309325

15. Hitt LM, Frei FX (2002) Do better customers utilize electronic distribution channels? The case of PC banking. Manag Sci 48(6): 732-748

16. Hoffman S, Lannes B, Dai J (2012) China e-commerce: heading toward RMB 1.5 trillion. http://www.bain.com/Images/BAIN BRIEF_China_e-commerce.pdf. Accessed 1 Sep 2014
17. http://businesstoday.intoday.in/story/cash-on-delivery-impact-on-ecommerce-companies-customers/1/202680.html

18. http://knowledge.wharton.upenn.edu/article/online-groceries-inindia-will-consumers-bite/, accessed on June 14, 2015

19. http://www.bain.com/Images/Value_online_customer_loyalty_ you_capture.pdf, accessed on June 21, 2015

20. http://www.bcg.com/media/PressReleaseDetails.aspx?id=tcm:12132905, accessed on June 21, 2015

21. Johnson MW, Christensen CM, Kagermann H (2008) Reinventing your business model. Harv Bus Rev 86(12):51-59

22. Kollmann T, Kuckertz A, Kayser I (2012) Cannibalization or synergy? Consumers' channel selection in online-offline multichannel systems. J Retail Consum Serv 19(2012):186-194

23. Kumar V, Patwari Y, Ayush HN (2008) Organised food retailing: a blessing or a curse? Econ Polit Wkly 43(20):67-75

24. Kwon WS, Lennon SJ (2009) What induces online loyalty? Online versus offline brand images. J Bus Res 62(5):557-564

25. Lewis J, Whysall P, Foster C (2014) Drivers and technology-related obstacles in moving to multichannel retailing. Int $\mathrm{J}$ Electron Commer 18(4):43-67

26. Michael L, Weitz B (2008) Retailing management, 7th edn. McGraw-Hill/Irwin, New York

27. Miller AD (1998) Theory of shopping. Polity, Cambridge

28. Moore RS, Kinard BR, Moore ML (2005) The carry-over effects of a physical store's image on its ecommerce distribution channel. Mark Manag J 15(1):59-68

29. Pantan E, Di Pietro 1 (2012) Understanding consumer's acceptance of technology-based innovations in retailing. J Technol Manag Innov 7(4):1-19

30. Pentina I, Pelton LE, Hasty RW (2009) Performance implications of online entry timing by store-based retailers: a longitudinal investigation. J Retail 85(2):177-193

31. Portal.euromonitor.com. Euromonitor International - Login 2014 Available at http://www.portal.euromonitor.com/Portal/Default. aspx Accessed 1 Sep 2014

32. Raijas A, Tuunainen VK (2001) "Critical factors in electronic grocery shopping”. Int Rev Retail, Distribut Cons Serv 11(3):255-265

33. Soh C, Mah QY, Gan FJ, Chew D, Reid E (1997) The use of the Internet for business: the experience of early adopters in Singapore. Internet Res 7(3):217-228

34. Sorescu A, Frambach RT, Singh J, Rangaswamy A, Bridges C (2011) Innovations in retail business models. J Retail 87S(1):S3S16

35. Venkatesan R, Kumar V, Ravishanker N (2007) Multichannel shopping: causes and consequences. J Mark 71(4):114-132

36. Verhoef PC, Neslin SA, Vroomen B (2007) Multichannel customer management: understanding the research-shopper phenomenon. Int J Res Mark 24(2):129-148

37. Viswanath V, James TYL, Xu X (2012) Consumer acceptance and use of information technology: extending the unified theory of acceptance and use of technology. MIS Q Vol. 36(No. 1):157-178

38. Widger Z, Bahl M (2012) Trends in India's e-commerce market. 2nd National Conference on e-Commerce, ASSOCHAM.

39. Xia Y, Zhang GP (2010) The impact of the online channel on retailers' performances: an empirical evaluation. Decis Sci 41(3): 517-546

40. Zott C, Amit R (2010) Business model design: an activity system perspective. Long Range Plan 43(2010):216-226 